\title{
Tumor angiogenesis as an important prognostic factor in advanced non-small cell lung cancer (Stage IIIA)
}

\author{
IVAN BAČIĆ ${ }^{1,2^{*}}$, ROBERT KARLO ${ }^{1,2^{*}}$, ANA ŠOŠTARIĆ ZADRO ${ }^{3}$, \\ ZVONKO ZADRO $^{4}$, NEVEN SKITARELIĆ ${ }^{2,5}$ and ANKO ANTABAK ${ }^{6}$
}

\begin{abstract}
${ }^{1}$ Department of Surgery, Zadar General Hospital; ${ }^{2}$ Department of Health Studies, University of Zadar, Zadar 23000; ${ }^{3}$ Department of Radiology, University Hospital for Infectious Diseases; ${ }^{4}$ Department of Surgery, University Hospital, Sveti Duh, University of Zagreb, Zagreb 10000; ${ }^{5}$ Department of Otorhinolaryngology, Zadar General Hospital, Zadar 23000; ${ }^{6}$ Surgery Clinic, University Hospital Centre Zagreb, Zagreb 10000, Croatia
\end{abstract}

Received August 21, 2017; Accepted November 7, 2017

DOI: $10.3892 / \mathrm{ol} .2017 .7576$

\begin{abstract}
The aim of the present study was to evaluate angiogenesis by determining the micro vascular density (MVD) and the expression of vascular endothelial growth factor (VEGF-A) in advanced non-small cell lung cancer (NSCLC) tumor samples, and to analyze their associations with clinical parameters and survival. Tumor tissue specimens of fifty patients (41 males and 9 females), who underwent radical surgical treatment for NSCLC in stage IIIA (T1-3N2) were collected for immunohistochemical analysis. MVD evaluation was performed using an anti-CD31 monoclonal antibody and VEGF-A expression using a polyclonal anti-VEGF-A antibody. The results were associated with two-year survival. Statistical analysis revealed significant associations in the level of angiogenesis (high MVD) and shorter survival of patients with NSCLC $(\mathrm{P}=0.0007)$. VEGF-A expression showed no association with micro vascular density $(\mathrm{P}=0.51)$ or survival $(\mathrm{P}=0.68)$. There was no significant association between MVD and VEGF-A. The measurable, clinical MVD parameters could be used as a reliable prognostic factor for the survival of patients with advanced NSCLC.
\end{abstract}

\section{Introduction}

Lung cancer is the most common malignant tumor and the leading cause of death from malignancies. Five-year survival of the lung cancer is around $15 \%$ (1). In patients with no distant metastases (M0), the status of mediastinal lymph nodes is crucial for the prognosis of the disease. Two-year and

Correspondence to: Dr Ivan Bačić, Department of Surgery, Zadar General Hospital, 5 Boze Pericica, Zadar 23000, Croatia

E-mail: ivan.bacic21@zd.t-com.hr

*Contributed equally

Key words: angiogenesis, blood vessel density, vascular endothelial growth factor-A, lung cancer, survival five-year survival of a patient with metastasis spreading to the mediastinal lymph nodes (stage IIIA-N2) treated with surgery and adjuvant chemotherapy is 50 and $22 \%$, respectively (2). TNM classification of malignant tumors, including lung cancer, is still the most accurate way of estimating the survival of patients with malignant tumors.

Angiogenesis is defined as the formation of new blood vessels from preexisting vessels. It is determined by complex interaction of multiple pro-angiogenic and anti-angiogenic factors. Angiogenesis is a prerequisite for tumor growth beyond 1-2 mm in diameter, when tumor cells can no longer be supplied with oxygen and nutrients by simple diffusion $(3,4)$. In order to increase in size, tumors undergo an angiogenic switch, where the action of pro-angiogenic factors leads to angiogenesis and tumor growth (5). Tumor blood vessels are irregular in shape and branching, disordered and have fragmented basement membrane, which makes them permeable to tumor cells and thus enable metastasis (6). Angiogenesis is estimated by determining the average density of tumor blood vessels (MVD).

VEGF-A is the most potent and specific pro-angiogenic factor. It plays a critical role in tumor growth and metastasis of epithelial tumors including colorectal cancer, breast cancer, renal cell cancer, cervical cancer as well as head and neck tumors and lung cancer (7-11). The binding of VEGF-A to its receptors triggers multiple signaling cascades resulting in endothelial cell proliferation, migration and differentiation. VEGF-A mediates increased vascular permeability promoting tumor dissemination via circulation. By induction of anti-apoptotic signals, such as bcl-2 and surviving, VEGF-A protects new vasculature from destruction $(12,13)$.

Although numerous studies point out that MVD is associated with the outcome of malignant tumors, the significance of MVD as a prognostic factor in patients with advanced NSCLC, who were initially surgically treated, was never investigated before (14). Furthermore, results of studies evaluating the prognostic significance of VEGF-A in NSCLC are controversial. High expression of VEGF-A, as a powerful pro-angiogenic factor, was correlated with high MVD in most studies (15-17).

In this retrospective study, we evaluated the prognostic significance of MVD and VEGF-A and their correlation with clinical parameters in advanced NSCLC (stage IIIA). MVD 
was assessed using CD31 and platelet endothelial cell adhesion molecule (PECAM-1), a protein found on the surface of endothelial cells. Immunohistochemical analysis was performed to evaluate the expression of CD 31 using a monoclonal anti-CD31 antibody and VEGF-A expression using polyclonal anti-VEGF-A antibody.

\section{Materials and methods}

Tissues. From the archives of the Department of Pathology in Zadar General Hospital, 50 formalin fixed, paraffin embedded cancer specimens were obtained from patients with histologically confirmed metastases to mediastinal lymph nodes, without distant metastases. The surgery on these patients was performed at the Department of Thoracic Surgery, Zadar General Hospital, Croatia between March1, 2007 and March 1, 2009. Samples from patients who died within 2 months of surgery were excluded from the study to eliminate perioperative complications as the cause of death. No patient underwent neoadjuvant chemotherapy or radiation therapy.

Histo-pathological properties of tumors were classified according to the World Health Organization. All patients received the same chemotherapy protocols postoperatively. The organization and stage of tumors were determined according to the guidelines of the International Association for the Study of Lung Cancer (IASLC) (18). Immunohistochemical analysis of tumor tissue samples was performed at the Department of Pathology, University of Rijeka School of Medicine. Patient survival was followed for a period of two years. Data on patients' survival were obtained from the Croatian National Cancer Registry. This study was approved by the Ethics Committee of Zadar General Hospital.

Immunohistochemical analysis. In each paraffin block, new sections were obtained and stained with hematoxylin eosin (HE) to determine a representative tumor area. The selected area of tumor tissue was transferred to the donor paraffin block and samples were taken from three different areas, to create tissue microarrays (TMA). With MTA Booster OI (Alphelys, Plaisir, France), 3 tissue cores, each measuring $1 \mathrm{~mm}$ in diameter, were taken from the marked spot on donor block and transferred into a new recipient paraffin block (recipient block microarrays) at given coordinates. The recipient paraffin block was left overnight at $45^{\circ} \mathrm{C}$ for tissue cores from the donor block to interconnect with the recipient block. Four $\mu \mathrm{m}$ thick sections were cut from the TMA block for immunohistochemical analysis. After drying, samples were deparaffinized in xylene and rehydrated in ethanol.

Sections were incubated with anti-CD31 monoclonal antibodies (1/50 dilution, JC70; NeoMarkers, Freemont, California, USA) at room temperature for $30 \mathrm{~min}$ in order to visualize the blood vessels. Positive controls were endothelial cells in normal blood vessels of the lungs.

Sections were incubated with the anti-VEGF-A polyclonal antibodies (A-20, 1/200 dilution; Santa Cruz Biotechnology, Santa Cruz, California, USA) at room temperature for two $h$ to determine VEGF-A (Fig. 1).

Microvessel counting was used to evaluate angiogenesis. Tumor sections stained with CD 31 were examined at low magnification $(x 40)$ to determine areas with the greatest vessel density (hot spots). Counting of blood vessels to determine

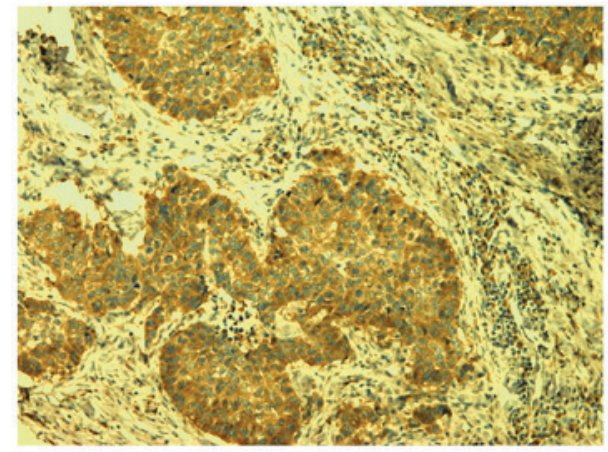

Figure 1. Vascular endothelial growth factor-A positive staining (magnification, x100).

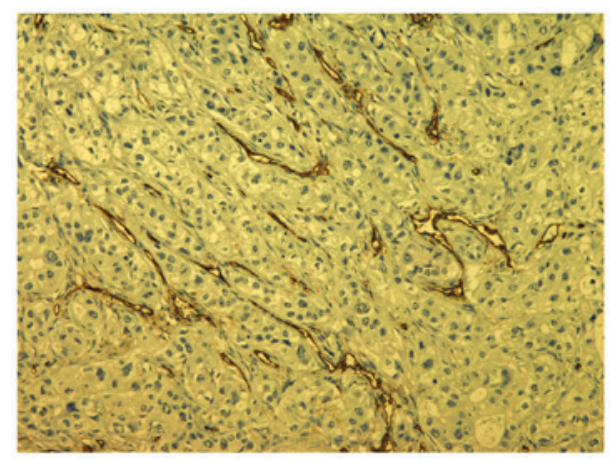

Figure 2. CD31 immunostaining (magnification, x100).

MVD was performed at high magnification (x400) in selected areas (Fig. 2).

Individual endothelial cells or clusters of endothelial cells with barely visible lumen or no lumen were considered individual vessels and therefore included in the analysis.

VEGF-A expression was assessed semi quantitatively by estimating the percentage of tumor cells stained on tumors slides. Four groups were formed as follows: 1) Positive staining in less than $25 \%$ of tumor cells; 2) positive staining in 25 to $50 \%$ of tumor cells; 3 ) positive staining in 50 to $75 \%$ of e tumor cells and 4) positive staining in more than $75 \%$ of tumor cells. The intensity of smooth muscle cells' staining in the blood vessels walls was positive internal control.

'Statistica 10' software program (StatSoft, Inc, Tulsa , Oklahoma, USA) was used for statistical analysis. Chi-square test with Yeates's correction was used to assess the correlations between MVD and VEGF-A with clinical parameters and with survival. Values of $\mathrm{P}<0.05$ were considered statistically significant. Survival curves were determined by Kaplan-Meier's method.

\section{Results}

The average age of patients was 63 years (ranging between 41 and 80), and there were 9 women and 41 men. There were 28 adenocarcinomas (56\%) and 22 squamous cell carcinomas (44\%) in our tissue sample. Macroscopic features of the primary tumors were estimated as follows: T1 tumors were found in $8(16 \%)$ patients, T2 in 19 patients (38\%) and T3 tumors in 23 patients (46\%). Noninvasive and invasive 'staging' was conducted with all 
Table I. Associations between micro vascular density, and clinicopathological parameters and survival.

\begin{tabular}{|c|c|c|c|}
\hline \multirow[b]{2}{*}{ Clinicopathological parameters } & \multicolumn{2}{|c|}{ MVD } & \multirow[b]{2}{*}{ P-value } \\
\hline & $\geq 17, \mathrm{n}(\%)$ & $<17, \mathrm{n}(\%)$ & \\
\hline \multicolumn{4}{|l|}{ Age, years } \\
\hline$>63$ & $9(18)$ & $14(28)$ & \multirow[t]{2}{*}{0.2400} \\
\hline$<63$ & $15(30)$ & $12(24)$ & \\
\hline \multicolumn{4}{|l|}{ Gender } \\
\hline Male & $17(34)$ & $24(48)$ & \multirow[t]{2}{*}{0.5900} \\
\hline Female & $5(10)$ & $4(8)$ & \\
\hline \multicolumn{4}{|l|}{ pT } \\
\hline 1,2 & $12(24)$ & $15(30)$ & \multirow[t]{2}{*}{0.3900} \\
\hline 3 & $13(26)$ & $10(20)$ & \\
\hline \multicolumn{4}{|l|}{ Histological type of NSCLC } \\
\hline Adenocarcinoma & $12(24)$ & $13(26)$ & \multirow[t]{2}{*}{1.0000} \\
\hline Squamous cell carcinoma & $12(24)$ & $13(26)$ & \\
\hline \multicolumn{4}{|l|}{ Differentiation } \\
\hline Good $(\mathrm{G} 1,2)$ & $11(22)$ & $16(32)$ & \multirow[t]{2}{*}{0.2600} \\
\hline Poor $(G 3,4)$ & $13(26)$ & $10(20)$ & \\
\hline \multicolumn{4}{|l|}{ Survival } \\
\hline$<24$ months & $18(36)$ & $6(12)$ & \multirow[t]{2}{*}{0.0007} \\
\hline$>24$ months & $6(12)$ & $20(40)$ & \\
\hline \multicolumn{4}{|l|}{ Expression of VEGF-A } \\
\hline $1(<25 \%)$ & $1(2)$ & $1(2)$ & \multirow[t]{4}{*}{0.5900} \\
\hline $2(25-50 \%)$ & $4(8)$ & $3(6)$ & \\
\hline $3(50-75 \%)$ & $11(22)$ & $13(26)$ & \\
\hline $4(>75 \%)$ & $11(22)$ & $6(12)$ & \\
\hline
\end{tabular}

MVD, micro vascular density; NSCLC, non-small cell lung cancer; VEGF-A, vascular endothelial growth factor-A.

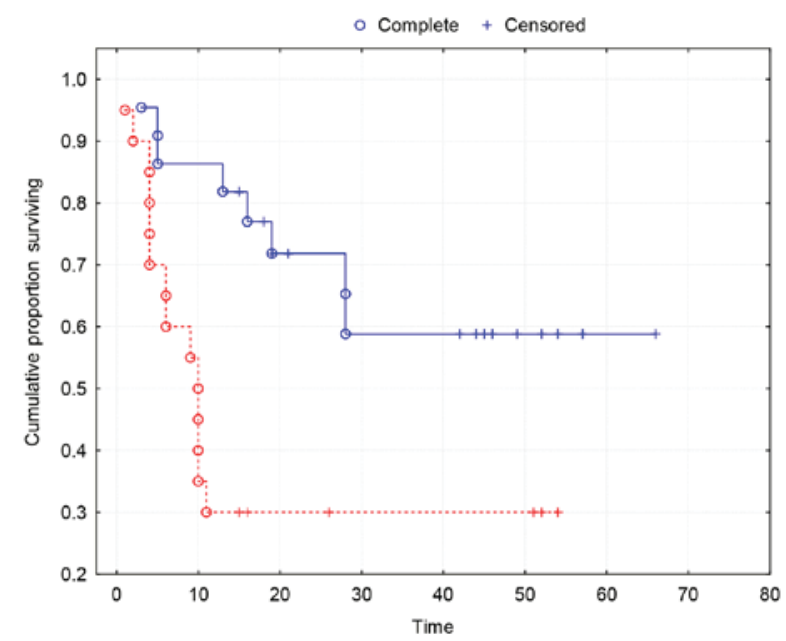

Figure 3. Kaplan-Meier's survival curves demonstrating a strong association between MVD and the two-year survival $(\mathrm{P}=0.0035)$. Group 0 (red line), tumors with $M V D \geq 17$. Group 1 (blue line), tumors with $M V D<17$. MVD, micro vascular density.

patients whereby tumor dissemination in mediastinal lymphatic nodes was not proved and neither in distant metastases.
The median MVD was 16.5 (range 8-30) and the mean of MVD values was 16.7 , so 17 is taken as cut-off value. Patients were classified into two groups: With low MVD $(<17)$ and high MVD ( $\geq 17)$. Low MVD was present in $26(52 \%)$ patients and high MVD in 24 (48\%) patients.

The overall two-year survival of patients in the study group was $52 \%$. The two-year survival of patients with high MVD was $21 \%$ and of patients with low MVD was $77 \%$. The results indicate a significantly increased survival of patients with low $\operatorname{MVD}\left(\chi^{2}=11.48\right.$; $\mathrm{P}=0.0007$ ) (Table I).

None of the standard clinically-relevant parameters (age, gender, histological type, $\mathrm{pT}$ and tumor differentiation) was significantly associated with MVD (Table I).

Kaplan-Meier survival curves show a strong association between MVD and two-year survival ( $\mathrm{P}=0.0035)$ (Fig. 3).

VEGF-A was highly expressed (positive staining in more than $50 \%$ of tumor cells) in the majority of tumors $(68 \%)$, but no association was found between VEGF-A expression and high MVD $(\mathrm{P}=0.59)$ (Table I).

VEGF-A expression was not associated with standard clinical parameters nor with survival $(\mathrm{P}>0.05)$ (Table II).

Kaplan-Maier survival curves show no correlation between VEGF-A and survival (Fig. 4). 
Table II. Associations between vascular endothelial growth factor-A expression, and clinicopathological parameters and survival.

$$
\text { Expression of VEGF-A }(\%)
$$

Clinicopathological parameters $\quad$ Group $1(<25 \%) \quad$ Group $2(25-50 \%) \quad$ Group $3(50-75 \%) \quad$ Group $4(>75 \%) \quad$ P-value

\begin{tabular}{|c|c|c|c|c|c|}
\hline \multicolumn{6}{|l|}{ Age (years) } \\
\hline$>63$ & 1 & 7 & 12 & 6 & \multirow[t]{2}{*}{0.77} \\
\hline$<63$ & 1 & 4 & 10 & 9 & \\
\hline \multicolumn{6}{|l|}{ Gender } \\
\hline Male & 1 & 8 & 19 & 13 & \multirow[t]{2}{*}{0.95} \\
\hline Female & 1 & 3 & 3 & 2 & \\
\hline \multicolumn{6}{|l|}{ pT } \\
\hline 1,2 & 0 & 6 & 11 & 7 & \multirow[t]{2}{*}{0.92} \\
\hline 3 & 2 & 5 & 11 & 8 & \\
\hline \multicolumn{6}{|l|}{ Histological type of NSCLC } \\
\hline Adenocarcinoma & 1 & 5 & 14 & 6 & \multirow[t]{2}{*}{0.82} \\
\hline Squamous cell carcinoma & 1 & 6 & 8 & 9 & \\
\hline \multicolumn{6}{|l|}{ Differentiation } \\
\hline Good $(\mathrm{G} 1,2)$ & 1 & 7 & 17 & 9 & \multirow[t]{2}{*}{0.87} \\
\hline Poor $(\mathrm{G} 3,4)$ & 1 & 4 & 5 & 6 & \\
\hline \multicolumn{6}{|l|}{ Survival (months) } \\
\hline$<24$ & 1 & 3 & 12 & 8 & \multirow[t]{2}{*}{0.62} \\
\hline$>24$ & 1 & 8 & 10 & 7 & \\
\hline
\end{tabular}

VEGF-A, vascular endothelial growth factor-A; NSCLC, non-small cell lung cancer.

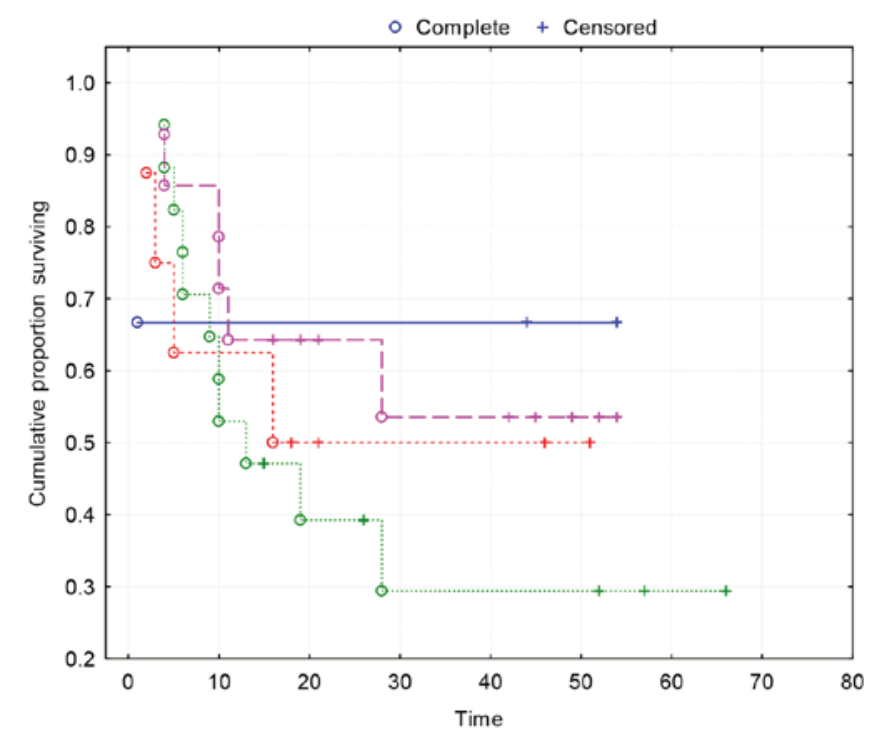

Figure 4. Kaplan-Meier curves demonstrating no association between VEGF-A and survival ( $\mathrm{P}=0.73$ ). Group 1 (blue line), VEGF-A expression $<25 \%$; Group 2 (red line), VEGF-A expression 25-50\%; Group 3 (green line), VEGF-A expression 50-75\%; Group 4 (purple line), VEGF-A expression $>75 \%$. VEGF-A, vascular endothelial growth factor-A.

\section{Discussion}

Lung cancer is the most common malignant tumor and the leading cause of death from malignancies. Five-year survival of lung cancer is around $15 \%$ (1). Despite the overall decreasing trend,
Croatia is still among the European countries with the highest male lung cancer incidence and mortality (19). TNM stage is the most important predictor of outcome in patients with NSCLC. However, patients within the same stage or tumor usually have a very variable prognosis, which depends not only on the stage, but also on the biological characteristics of the tumor. Angiogenesis was validated as an independent prognostic factor in a variety of solid malignancies. Several studies demonstrated that angiogenesis, assessed by MVD, is a significant prognostic factor for patients with NSCLC (3,7,20-23). However, most studies have been conducted on patients with NSCLC in early stages and studies dealing specifically with the prognostic impact of angiogenesis in NSCLC with metastasis in mediastinal lymph nodes are lacking. The only study, to our knowledge, which examines the impact of angiogenesis on prognosis of patients in stage IIIA (T1-3N2), who were initially surgically treated, was performed by Angeletti and al. in 1996 and in this study MVD was identified as a significant prognostic factor (23).

Several studies have not found MVD to be a predictor of survival (24-26).

Since those papers did not prove the correlation MVD and survival it is obvious that the role of tumor angiogenesis prognosis in the disease's survival is still controversial, we decided to examine the correlation MVD and survival with our patients by using CD 31 monoclonal antibodies to visualize the blood vessels instead of anti-factor VII polyclonal antibodies which were used in the mentioned researches.

The results of studies which examined the correlation of VEGF-A and survival of patients with NSCLC are 
controversial. Although many data support the statement that the VEGF-A is correlated with MVD and survival (16,25-27), others did not confirm VEGF-A as an independent factor of survival (28-30). The prognostic significance of VEGF-A in patients with advanced NSCLC, who were primary surgically treated, has never been investigated. In our study, we observed the high expression of VEGF-A in most patients, but there was no correlation with MVD and survival. This lack of correlation indicates that other angiogenic factors may have an important role in angiogenesis in advanced NSCLC.

Our study is retrograded and includes patients with metastases to mediastinal lymph nodes that were discovered during thoracotomy and subsequent histopathological examination, and for these reasons were not subjected to neoadjuvant chemotherapy.

All patients included in the study received adjuvant chemotherapy according to the appropriate protocol and in full dose. Not one of the patients was subjected to anti-VEGF antibodies (bevacizumab) therapy. Our results show that patients who were classified by TNM classification in the same prognostic stage have a highly variable prognosis. We found that high MVD has a strong negative prognostic value for survival of patients with lung cancer.

The introduction of anti-angiogenic therapy in cancer treatment makes methods of angiogenesis evaluation even more important. Patients with highly vascularized tumors, due to their worse prognosis, may be candidates for more aggressive therapy especially neoadjuvant multimodal chemotherapy. Assessment of angiogenesis can become an integral part of the tumor staging and ultimately helping to choose the most efficient therapeutic approach.

\section{References}

1. Jemal A, Siegel R, Ward E, Hao Y, Xu Y, Murray T and Thun MJ: Cancer statistics, 2008. CA Cancer J Clin 58: 71-96, 2008.

2. Pisters KM and Darling G: The IASLC lung cancer staging project: 'The Nodal Zone'. J Thorac Oncol 2: 583-584, 2007.

3. Weidner N: Intratumor microvessel density as a prognostic factor in cancer. Am J Pathol 147: 9-19, 1995.

4. Folkman J: The role of angiogenesis in tumor growth. Semin Cancer Biol 3: 65-71, 1992.

5. Cox G,Jones JL, WalkerRA,Steward WP and O'Byrne KJ: Angiogenesis and non-small cell lung cancer. Lung Cancer 27: 81-100, 2000.

6. Fox SB, Gatter KC and Harris AL: Tumour angiogenesis. J Pathol 179: 232-237, 1996.

7. Mineo TC, Ambrogi V, Baldi A, Rabitti C, Bollero P, Vincenzi B and Tonin G: Prognostic impact of VEGF, CD31, CD34, and CD105 expression and tumour vessel invasion after radical surgery for IB-IIA non-small cell lung cancer. J Clin Pathol 57: 591-597, 2004.

8. Abu-Jawdeh GM, Faix JD, Niloff J, Tognazzi K, Manseau E, Dvorak HF and Brown LF: Strong expression of vascular permeability factor (vascular endothelial growth factor) and its receptors in ovarian borderline and malignant neoplasms. Lab Invest 74: 1105-1115, 1996.

9. Claffey KP, Brown LF, del Aguila LF, Tognazzi K, Yeo KT, Manseau EJ and Dvorak HF: Expression of vascular permeability factor/vascular endothelial growth factor by melanoma cells increases tumor growth, angiogenesis, and experimental metastasis. Cancer Res 56: 172-181, 1996.

10. Maeda K, Chung YS, Ogawa Y, Takatsuka S, Kang SM, Ogawa M, Sawada T and Sowa M: Prognostic value of vascular endothelial growth factor expression in gastric carcinoma. Cancer 77: 858-863, 1996.

11. Takahashi Y, Kitadai Y, Bucana CD, Cleary KR and Ellis LM: Expression of vascular endothelial growth factor and its receptor, KDR, correlates with vascularity, metastasis, and proliferation of human colon cancer. Cancer Res 55: 3964-3968, 1995.

12. Maharaj AS, Saint-Geniez M, Maldonado AE and D'Amore PA: Vascular endothelial growth factor localization in the adult. Am J Pathol 168: 639-648, 2006.
13. Ferrera N: Vascular endothelial growth factor. Trends Cardiovasc Med 3: 244-250, 1993.

14. Meert AP, Paesmans M, Martin B, Delmotte P, Berghmans T, Verdebout JM, Lafitte JJ, Mascaux C and Sculier JP: The role of microvessel density on the survival of patients with lung cancer: A systematic review of the literature with meta-analysis. Br J Cancer 87: 694-701, 2002.

15. Kadota K, Huang CL, Liu D, Ueno M, Kushida Y, Haba R and Yokomise H: The clinical significance of lymphangiogenesis and angiogenesis in non-small cell lung cancer patients. Eur J Cancer 44: 1057-1067, 2008.

16. Fontanini G, Vignati S, Boldrini L, Chinè S, Silvestri V, Lucchi M, Mussi A, Angeletti CA and Bevilacqua G: Vascular endothelial growth factor is associated with neovascularization and influences progression of non-small cell lung carcinoma. Clin Cancer Res 3: 861-865, 1997.

17. Han H, Silverman JF, Santucci TS, Macherey RS, d'Amato TA, Tung MY, Weyant RJ and Landreneau RJ: Vascular endothelial growth factor expression in stage I non-small cell lung cancer correlates with neoangiogenesis and a poor prognosis. Ann Surg Oncol 8: 72-79, 2001.

18. International Association for the Study of Lung Cancer and Peter Goldstraw. IASLC Staging Manual in Thoracic Oncology. Orange Park, Editorial Rx Press, 2009.

19. Janković M, Samarzija M, Jakopović M, Kulis T and Znaor A: Trends in lung cancer incidence and mortality in Croatia, 1988-2008. Croat Med J 53: 93-99, 2012.

20. Matsuyama K, Chiba Y, Sasaki M, Tanaka H, Muraoka R and Tanigawa N: Tumor angiogenesis as a prognostic marker in operable non-small cell lung cancer. Ann Thorac Surg 65: 1405-1409, 1998.

21. Macchiarini P, Fontanini G, Hardin MJ, Squartini F and Angeletti CA: Relation of neovascularization to metastasis of non-small cell lung cancer. Lancet 340: 145-146, 1992.

22. Giatromanolaki A, Koukourakis MI, Theodossiou D, Barbatis K, O'Byrne K, Harris AL and Gatter KC: Comparative evaluation of angiogenesis assessment with anti-factor-VIII and anti-CD31 immunostaining in non-small cell lung cancer. Clin Cancer Res 3: 2485-9224, 1997.

23. Angeletti CA, Lucchi M, Fontanini G, Mussi A, Chella A, Ribechini A, Vignati S and Bevilacqua G: Prognostic significance of tumoral angiogenesis in completely resected late stage lung carcinoma (stage IIIA-N2). Impact of adjuvant therapies in a subset of patients at high risk of recurrence. Cancer 78: 409-415, 1996.

24. Chandrachud LM, Pendleton N, Chisholm DM, Horan MA and Schor AM: Relationship between vascularity, age and survival in non-small-cell lung cancer. Br J Cancer 76: 1367-1375, 1997.

25. Pastorino U, Andreola S, Tagliabue E, Pezzella F, Incarbone M, Sozzi G, Buyse M, Menard S, Pierotti M and Rilke F: Immunocytochemical markers in stage I lung cancer: Relevance to prognosis. J Clin Oncol 15: 2858-2865, 1997.

26. Imoto $\mathrm{H}$, Osaki $\mathrm{T}$, Taga S, Ohgami A, Ichiyoshi $\mathrm{Y}$ and Yasumoto K: Vascular endothelial growth factor expression in non-small-cell lung cancer: Prognostic significance in squamous cell carcinoma. J Thorac Cardiovasc Surg 115: 1007-1014, 1998

27. Iwasaki A, Kuwahara M, Yoshinaga Y and Shirakusa T: Basic fibroblast growth factor (bFGF) and vascular endothelial growth factor (VEGF) levels, as prognostic indicators in NSCLC. Eu J Cardio-Thoracic Surg 25: 443-448, 2004.

28. Bonnesen B, Pappot H, Holmstav J and Skov BG: Vascular endothelial growth factor A and vascular endothelial growth factor receptor 2 expression in non-small cell lung cancer patients: Relation to prognosis. Lung Cancer 66: 314-318, 2009.

29. Yano T, Tanikawa S, Fujie T, Masutani M and Horie T: Vascular endothelial growth factor expression and neovascularisation in non-small cell lung cancer. Eur J Cancer 36: 601-609, 2000

30. Decaussin M, Sartelet H, Robert C, Moro D, Claraz C, Brambilla $C$ and Brambilla E: Expression of vascular endothelial growth factor (VEGF) and its two receptors (VEGF-R1-Flt1 and VEGF-R2-Flk1/KDR) in non-small cell lung carcinomas (NSCLCs): Correlation with angiogenesis and survival. J Pathol 188: 369-377, 1999.

This work is licensed under a Creative Commons Attribution-NonCommercial-NoDerivatives 4.0 International (CC BY-NC-ND 4.0) License. 